\title{
Adrenal Cortical Function in the Postmature Fetus and Newborn Infant
}

\author{
BRENDA J. BARNHART, CHRISTINA VERT CARLSON, AND JOHN W. REYNOLDS ${ }^{(15)}$ \\ Department of Pediatrics, University of Oregon Health Sciences Center, Portland, Oregon, USA
}

\begin{abstract}
Summary
The umbilical venous blood concentrations of cortisol, dehydroepiandrosterone sulfate (DHAS), and unconjugated estriol were compared in 54 normal, 37 postterm, and 22 postmature newborns. Pre- and postadrenocorticotropic hormone (ACTH) stimulation levels of serum cortisol and DHAS were compared in the first 2 to 4 days of life in 19 postterm and 15 postmature infants. Comparison was also made between vaginally and cesarean section delivered postterm and postmature newborns. There were significantly greater cord blood cortisol levels in the postmature $[260 \pm 22 \mathrm{ng} / \mathrm{ml}( \pm$ S.E. $)]$, than in the normal $(193 \pm 11$ $\mathrm{ng} / \mathrm{ml})(P<0.01)$ or postterm $(193 \pm 18 \mathrm{ng} / \mathrm{ml})(0.01<P<0.05)$ vaginally delivered infants. There were no significant differences in the mean cord blood DHAS levels in the three groups (normal, $2645 \pm 130 \mathrm{ng} / \mathrm{ml}$; postterm, $2323 \pm 188 \mathrm{ng} / \mathrm{ml}$; postmature, 2310 $\pm 224 \mathrm{ng} / \mathrm{ml}$ ). Cortisol and DHAS responses to ACTH stimulation were the same in the postterm and postmature groups. There was a significantly lower mean umbilical venous unconjugated estriol level in the vaginally delivered postmature group $(75 \pm 11 \mathrm{ng} / \mathrm{ml})$ as compared to values in vaginally delivered postterm $[120 \pm 14$ $\mathrm{ng} / \mathrm{ml}(P=0.01)]$ and normal $[144 \pm 10 \mathrm{ng} / \mathrm{ml}(P<0.002)]$ newborns. Stressed postmature infants delivered by cesarean section had higher unconjugated estriol levels $(83 \pm 12 \mathrm{ng} / \mathrm{ml})$ than their unstressed, postterm cesarean section controls $[40 \pm 9 \mathrm{ng}$ / $\mathrm{ml}(P<0.01)$, but levels were still below those from vaginally delivered postterm infants. These findings substantiate normal adrenal function in the postmature fetus and newborn. Lowered umbilical venous unconjugated estriol levels in the postmature infants at birth appear to be a function of limited aromatizing activity of the placenta rather than due to low levels of fetal adrenal-derived neutral steroid substrate.
\end{abstract}

\section{Speculation}

Early in the development of placental insufficiency, placental conversion of fetal-derived neutral steroid estrogen precursors is the limiting factor in estrogen production in the feto-placental unit. Whether estrogen precursor production by the fetus also becomes an important factor in decreased feto-placental estrogen production as placental insufficiency progresses has not been determined.

\section{INTRODUCTION}

A postmature infant is one born at greater than $42 \mathrm{wk}$ gestation with evidence of dysmaturity, whereas a postterm infant is one born at more than $\mathbf{4 2}$ wk gestation but with no abnormal physical findings. Clifford (2) classified postmaturity into three stages with the stage $I$ infant showing loss of vernix, skin maceration, malnutrition with loss of fat, and an open-eyed and alert appearance. An infant with stage II postmaturity had the characteristics of stage I plus meconium-filled amniotic fluid, meconium-covered skin, green meconium staining of the placental membranes and umbilical cord, and evidence of fetal distress or anoxia. Stage III showed all the characteristics of the first two with evidence of chronic asphyxia, a dirty yellow or yellow-green cord, and yellowstained nails and skin (2). Mortality was reported as high as $50 \%$ in the acutely distressed stage II infants. Postmature newborns have twice the perinatal mortality as term babies (14), with the overall postterm mortality rate at 5 to $7 \%$ (13). Postmature newborns are prone to develop hypoglycemia, asphyxic organ dysfunction, and pulmonary aspiration syndrome. There is some evidence that postmature babies may have neurologic abnormalities which persist as learning disabilities when they reach school age (6).

The possibility that the delayed onset of labor in pregnancies with a postmature fetus might be secondary to decreased fetal cortisol secretion was raised by Nwosu et al. $(9,10)$. They found that cortisol levels at 8 to $36 \mathrm{hr}$ of age were lower in postmature babies than in their controls. Amniotic fluid analysis by the same group, however, failed to demonstrate significantly lower cortisol in the postmature than in the postterm babies (7). In spite of the lower resting cortisol levels, a normal cortisol rise followed adrenocorticotropic hormone (ACTH) administration in the postmature group (8). They concluded that there seemed to be no primary adrenal insufficiency present in these babies, but that there was perhaps an inadequately functioning hypothalamic-pituitary axis (8). In this study, we have examined adrenocortical function in postmature and postterm infants by measuring cortisol and dehydroepiandrosterone sulfate (DHAS) before and after ACTH stimulation. In addition, we have evaluated the function of the fetoplacental unit by measuring umbilical venous cortisol, DHAS, and unconjugated estriol in these same infants and in normalterm control infants.

\section{MATERIALS AND METHODS}

This study was based on blood samples from 116 infants born at the University of Oregon Health Sciences Center between November, 1977, and March, 1979. Cord blood was obtained from 57 normal, 37 postterm, and 22 postmature newborns. Nine of the postterm infants were delivered by cesarean section. The indications for surgery were cephalopelvic disproportion or failure to progress in labor. None of the fetuses showed evidence of fetal distress. Seven of the postmature infants were delivered by cesarean section, five for indications of fetal distress, and two for failure to progress in labor. Serial blood sampling from 12 to $96 \mathrm{hr}$ of age with ACTH stimulation done at two to four days of age was carried out in 19 of the postterm and 15 of the postmature babies. This clinical study was approved by the University of Oregon Committee on the Use of Human Subjects in Research, and consent was obtained from a parent in each case.

The clinical evaluation of gestational age and for evidence of dysmaturity was carried out by a single observer (B. J. B.). Normal newborns were infants delivered vaginally at 37 to 42 wk postconceptual age with Apgar scores greater than seven at 1 and 5 min Gestational age was based on the date of the last menstrual period, 
early prenatal exam, and/or an ultrasound examination. The postmature infants were those greater than 42 wk gestation who showed at least three of the characteristics of dysmaturity detailed in the "Introduction." The majority of the babies were classified as stage I with no baby falling into the stage III category. Postterm infants were those who were greater than $42 \mathrm{wk}$ who showed no more evidence of dysmaturity than mild peeling of the skin without loss of subcutaneous tissue or had terminal meconium noted at delivery. Omitted from this study were infants with multiple congenital malformations, congenital viral illness, infants of diabetic mothers, or infants who required respiratory support after birth.

Adrenal stimulation was carried out by the administration of $0.25 \mathrm{mg}$ cosyntropin (Cortrosyn). A pre-ACTH stimulation blood sample was obtained immediately before intravenous (IV) injection of cosyntropin. The poststimulation sample was drawn 60 min later. All blood was obtained from an antecubital vein or by capillary heel stick. The serum was separated and frozen until assayed.

\section{PROCEDURE FOR SERUM DHAS ASSAY}

The procedure for DHAS assay was described by Turnipseed $e t$ al. (12). The cross-reactivities are the same as reported in that paper.

\section{PROCEDURE FOR UNCONJUGATED ESTRIOL ASSAY}

The plasma extraction procedure was that of Katagiri et al. (4), and the remainder of the radioimmunoassay followed the procedure presented by Reynolds $e t$ al. (11) except that no acid hydrolysis was carried out. The antibody used was the same as used by Reynolds et al. (11).

\section{PROCEDURE FOR CORTISOL ASSAY}

A GammaCoat $I^{125}$ cortisol radioimmunoassay kit from Clinical Assays (Travenol Laboratories, Inc., Cambridge, MA) was used. Percentage of cross-reactivity was: cortisol, $100 \%$; 11-deoxycortisol, 7.6\%; cortisone, $5.6 \%$ corticosterone, $3.3 \%$; $17-\mathrm{OH}$ progesterone, $0.2 \%$; and progesterone, $<0.1 \%$.

\section{RESULTS}

Table 1 presents the mean \pm S.E. cord blood levels of cortisol, DHAS, and unconjugated estriol. There were 54 normal vaginally delivered babies with a mean cortisol level of $193 \mathrm{ng} / \mathrm{ml}$. Mean cortisol level for 28 vaginally delivered postterm babies was 193 $\mathrm{ng} / \mathrm{ml}$, and for the cesarean section delivered postterm babies, it was $142 \mathrm{ng} / \mathrm{ml}$. There was no significant difference between the normal and postterm vaginally delivered infants or between the vaginally and cesarean section delivered postterm infants. The vaginally delivered postmature babies had a mean cortisol level of $260 \mathrm{ng} / \mathrm{ml}$, and the cesarean section-delivered, postmature infants

Table 1. Mean cord blood levels of cortisol, DHAS, and unconjugated estriol

\begin{tabular}{ccccc}
\hline Group & $\begin{array}{c}\text { No. of } \\
\text { cases }\end{array}$ & $\begin{array}{c}\text { Cortisol } \\
(\mathrm{ng} / \mathrm{ml})\end{array}$ & $\begin{array}{c}\text { DHAS } \\
(\mathrm{ng} / \mathrm{ml})\end{array}$ & $\begin{array}{c}\text { Unconjugated } \\
\text { estriol }(\mathrm{ng} / \mathrm{ml})\end{array}$ \\
\hline Normal vaginal & 54 & $193 \pm 11^{1}$ & $2645 \pm 130$ & $144 \pm 10$
\end{tabular}

\begin{tabular}{lrrrr}
$\begin{array}{l}\text { Postterm } \\
\quad \text { Vaginal }\end{array}$ & 28 & $193 \pm 18$ & $2323 \pm 188$ & $120 \pm 14$ \\
$\begin{array}{l}\text { Cesarean sec- } \\
\text { tion }\end{array}$ & 9 & $142 \pm 29$ & $1878 \pm 469$ & $40 \pm 9$ \\
& & & & \\
$\begin{array}{l}\text { Postmature } \\
\quad \text { Vaginal }\end{array}$ & 15 & $260 \pm 22$ & $2310 \pm 224$ & $75 \pm 11$ \\
$\begin{array}{l}\text { Cesarean sec- } \\
\text { tion }\end{array}$ & 7 & $213 \pm 34$ & $2710 \pm 660$ & $83 \pm 12$ \\
\hline
\end{tabular}

\footnotetext{
${ }^{1}$ Mean \pm S.E.
}

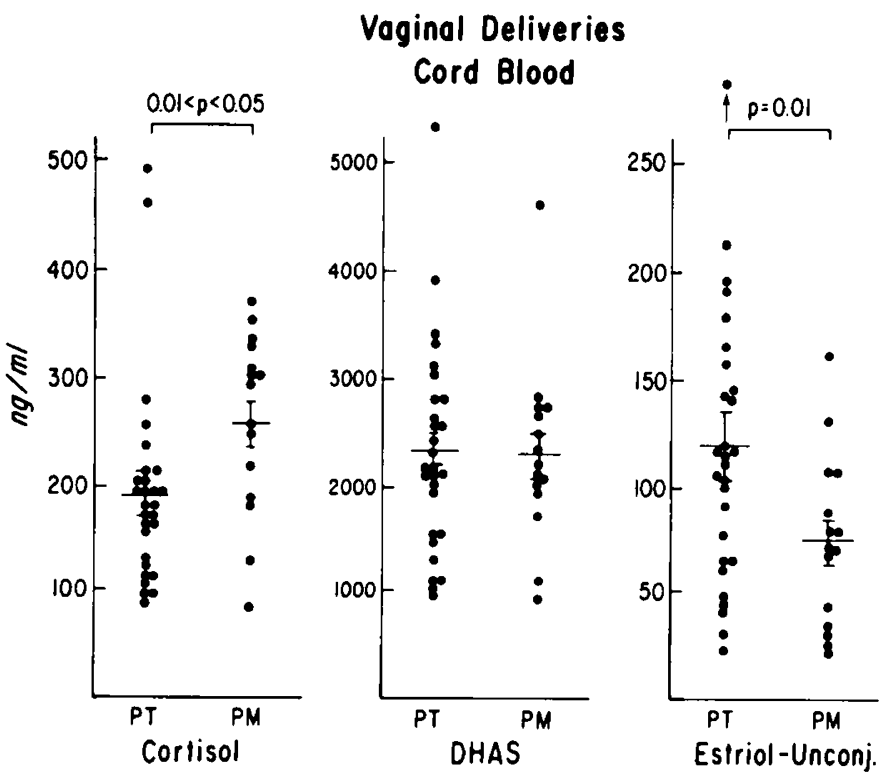

Fig. 1. Umbilical venous levels of cortisol, DHAS, and unconjugated estriol in postterm and postmature newborns.

had a mean cortisol of $213 \mathrm{ng} / \mathrm{ml}$. These two values were not significantly different. The mean cortisol level of the vaginally delivered postmature infants was significantly greater than the mean level of the normal infants $(P<0.01)$ and that of the vaginally delivered postterm infants $(0.01<P<0.05)$ (Fig. 1). The cord blood levels of cortisol are higher than those recently reported by Kauppila et al. (5) who used quantification techniques including column chromatography of serum extracts followed by radioimmunoassay. The nature of the cross-reacting steroid(s) in our samples which give(s) the higher values is not identified because our cross-reactivity studies show that the antibody we used has a high degree of specificity. However, our cortisol levels should be used for intergroup comparisons in our study and not in comparisons with umbilical cord cortisol levels obtained in studies carried out in other laboratories using other assay materials and techniques.

The normal babies had a mean umbilical venous DHAS concentration of $2645 \mathrm{ng} / \mathrm{ml}$. The vaginally delivered postterm babies had a mean DHAS of $2323 \mathrm{mg} / \mathrm{ml}$, and the cesarean sectiondelivered postterm babies had a mean DHAS of $1878 \mathrm{ng} / \mathrm{ml}$. The mean DHAS for the vaginally delivered, postmature group was $2310 \mathrm{ng} / \mathrm{ml}$, and for the cesarean section postmature group, it was $2701 \mathrm{ng} / \mathrm{ml}$. There were no statistically significant differences in the levels of DHAS among any of these groups.

The mean unconjugated estriol level in the normal infants was $144 \mathrm{ng} / \mathrm{ml}$. The mean unconjugated estriol level in the postterm, vaginally delivered group was $120 \mathrm{ng} / \mathrm{ml}$, which was significantly higher $(P<0.002)$ than the mean value of $40 \mathrm{ng} / \mathrm{ml}$ in the postterm, cesarean section-delivered group. There was no significant difference between the mean unconjugated estriol levels in the vaginally delivered postterm and the normal control groups. The postmature, vaginally delivered infants had a mean estriol level of $75 \mathrm{ng} / \mathrm{ml}$, and the postmature, cesarean section-delivered infants had a mean estriol level of $83 \mathrm{ng} / \mathrm{ml}$. Both postmature groups were significantly lower than the normal group $(P<$ 0.002 ). The strikingly low level of estriol in the cesarean sectioned, postterm infants was significantly lower $(0.002<P<0.01)$ than the mean value of the cesarean sectioned, postmature group. In contrast, the vaginally delivered postterm babies had a higher ( $P$ $=0.01$ ) mean estriol level than did their postmature counterparts (Fig. 1).

Stimulation tests were not performed on the normal control babies. ACTH stimulation was carried out on 19 of the postterm and 15 of the postmature infants (see Table 2 ). The mean prestimulation cortisol level in the postterm group was $123 \mathrm{ng} / \mathrm{ml}$, with 
Table 2. Results of adrenocorticotropic hormone stimulation

\begin{tabular}{lcc}
\hline & Cortisol $(\mathrm{ng} / \mathrm{ml})$ & DHAS $(\mathrm{ng} / \mathrm{ml})$ \\
\hline Postterm & $123 \pm 18^{\prime}$ & $1376 \pm 158$ \\
$\quad$ Prestimulation & $422 \pm 25$ & $3522 \pm 363$ \\
$\quad$ Poststimulation & & \\
$n=19$ & $298 \pm 29$ & $2146 \pm 357$ \\
$\quad \begin{array}{l}\text { Difference } \\
\% \text { difference }\end{array}$ & $440 \pm 95$ & $188 \pm 31$ \\
Postmature & $136 \pm 17$ & $1436 \pm 205$ \\
$\quad$ Prestimulation & $486 \pm 43$ & $3056 \pm 257$ \\
$\quad$ Poststimulation & & \\
$n=15$ & $350 \pm 40$ & $1620 \pm 163$ \\
$\quad$ Difference & $318 \pm 49$ & $131 \pm 14$ \\
\hline difference & &
\end{tabular}

1 Mean \pm S.E.

a poststimulation rise to $422 \mathrm{ng} / \mathrm{ml}$. The mean increase was 298 $\mathrm{ng} / \mathrm{ml}$, and percentage of change was $440 \%$. The postmature babies responded similarly with a mean prestimulation cortisol value of $136 \mathrm{ng} / \mathrm{ml}$, a poststimulation value of $486 \mathrm{ng} / \mathrm{ml}$, a change of $350 \mathrm{ng} / \mathrm{ml}$, and a percentage of change of $318 \%$.

The DHAS levels rose from $1376 \mathrm{ng} / \mathrm{ml}$ pre-ACTH stimulation to $3522 \mathrm{ng} / \mathrm{ml}$ poststimulation in postterm infants. The mean increase was $2146 \mathrm{ng} / \mathrm{ml}$, and the percentage of increase was $188 \%$. The postmature babies had prestimulation DHAS values of $1436 \mathrm{ng} / \mathrm{ml}$ and poststimulation value of $3056 \mathrm{ng} / \mathrm{ml}$. The mean increase was $1620 \mathrm{ng} / \mathrm{ml}$, representing a percentage increase of $131 \%$. There were no significant differences between the postterm and the postmature infants in their prestimulation plasma cortisol and DHAS levels, and no differences in their cortisol or DHAS responses to ACTH stimulation.

\section{DISCUSSION}

The purpose of our study was to evaluate the adrenocortical function of postmature fetuses using postterm infants as their controls. In addition, placental steroid metabolizing function was assessed through measurement of umbilical venous DHAS and unconjugated estriol levels.

There was no significant difference in umbilical venous cortisol levels between the normal and postterm vaginally and cesarean section-delivered babies. There was, however, a significantly higher cord blood cortisol value in both vaginal and cesarean section-delivered stressed postmature infants than in either of the postterm groups or the normal group. These cord blood levels are in contrast to the findings by Nwosu et al. $(9,10)$ that umbilical cord cortisol levels are the same in postmature newborns as in stressed and unstressed term infants. However, we did agree with Nwosu et al. (8) in our finding of a normal response to ACTH of cortisol levels, as well as DHAS levels, in postmature infants. Our cord blood cortisol values and the responses to exogenous ACTH stimulation indicated an adequate adrenal function and responsiveness to stimuli in these abnormal infants.

This study is the first to report umbilical cord DHAS levels in postterm and postmature fetuses. No differences were found between DHAS levels in normal, postterm, and postmature fetuses, regardless of mode of delivery. This finding confirms the adequacy of adrenocortical function in the postmature fetuses studied. The lack of significant elevation of cord DHAS levels in the stressed postmature infants, implying a lack of response to endogenous ACTH, may be related to the lesser percentage increase in DHAS, as compared to increase in cortisol, seen with postnatal exogenous ACTH stimulation.

Estriol excretion by pregnant women who are postterm has been used as an indicator of fetal health. Low estriol excretions have been considered evidence of fetal jeopardy and thus an indication for rapid delivery of the fetus. Maternal plasma unconjugated estriol levels have not been used extensively, but one study found no correlation between low maternal plasma levels in prolonged pregnancies and low Apgar scores or other neonatal problems (1).

Our findings of significantly lower umbilical cord serum unconjugated estriol levels in postmature newborns than in postterm newborns in the presence of DHAS levels which were not significantly different, provides useful information about the origin of the low maternal estriol excretion in postterm pregnancies with a jeopardized fetus. Low estriol production by the fetoplacental unit theoretically could be due to generalized fetal adrenocortical hypofunction, decreased production of estrogen precursors with preservation of cortisol secretion, or normal adrenal function with an underactivity of placental enzymatic conversion of neutral steroid precursors to estriol. In view of our findings of elevated cortisol levels, normal DHAS levels, and low unconjugated estriol levels, the limiting point in estriol production in the fetoplacental unit with a postmature fetus appears to be in placental conversion of neutral steroid precursors to estriol. An alternative explanation could be that the fetal hepatic $16 \alpha$-hydroxylation of DHAS to $16 \alpha-O H-D H A S$, the principal fetal-derived substrate for placental estriol synthesis, is limited in postmature pregnancies. No evidence for or against this hypothesis is available at present. Our finding of elevated cord cortisol levels and depressed cord unconjugated estriol levels in postmature newborns is similar to the cord serum steroid pattern described by Goldkrand (3) as characteristic of the chronically stressed pregnancy with fetal distress.

\section{REFERENCES AND NOTES}

1. Bashore, R. A., and Westlake, J. R.: Plasma unconjugated estriol values in high risk pregnancy. Am. J. Obstet. Gynecol., 128: 371 (1977).

2. Clifford. S. H.: Postmaturity. Adv. Pediatr., 9: 13 (1957).

3. Goldkrand, J. W.: Unconjugated estriol and cortisol in maternal and cord serum and amniotic fluid in normal and abnormal pregnancy. Obstet. Gynecol.. 52. 264 (1978).

4. Katagiri, H., Stanczyk. F. Z., and Goebelsmann. U.: Estriol in pregnancy. III. Development, comparison and use of specific antisera for rapid immunoassay of unconjugated estriol in pregnancy plasma. Steroids, 24: 225 (1974).

5. Kauppila, A., Koivisto, M., Pukka, M., and Tuimala, R.: Umbilical cord and neonatal cortisol levels. Obstet. Gynecol., 52: 666 (1978).

6. Lovell, K. E.: The effect of postmaturity on the developing child. Med. J. Aust. I: 13 (1973).

7. Nwosu, U. C., Bolognese, R. J., Wallach, E. E., and Bongiovanni, A. M.: Amniotic fluid cortisol concentrations in normal labor, premature labor and postmature pregnancy. Obstet. Gynecol., 49: 715 (1977).

8. Nwosu, U. C., Johnson, L., Bongiovanni. A. M., Boggs, T. R., and Wallach, E. E.: Adrenocortical response to ACTH stimulation in postmature newborns. Obstet. Gynecol., 52: 213 (1978).

9. Nwosu, U. C., Wallach, E. E., Boggs, T. R., Nemiroff, R. L., and Bongiovanni, A. M.: Possible role of the fetal adrenal glands in the etiology of postmaturity. Am. J. Obstet. Gynecol., 121: 366 (1975).

10. Nwosu U. C., Wallach. E. E., Boggs. T. R., and Bongiovanni, A. M.: Possible adrenocortical insufficiency in postmature neonates. Am. J. Obstet. Gynecol.. 122: 969 (1975)

11. Reynolds, J. W., Bentley, K., and Turnipseed, M. R.: Serum total estriol in abnormal newborn infants. J. Steroid Biochem., 8: 853 (1977).

12. Turnipseed, M. R., Bentley, K., and Reynolds, J. W.: Serum DHAS in premature infants and in infants with intrauterine growth retardation. J. Clin. Endocrinol. Metab., 43: 1219 (1976).

13. Vorherr, H.: Placental insufficiency in relation to postterm pregnancy and fetal postmaturity. Am. J. Obstet. Gynecol., 123: 67 (1975).

14. Zwerdling. M. A.: Factors pertaining to prolonged pregnancy and its outcome. Pediatrics, 40: 202 (1967).

15. Requests for reprints should be addressed to: John W. Reynolds. M.D., Department of Pediatrics. University of Oregon Health Sciences Center, Portland. OR 97201 (USA)

16. This research was supported by grants from the Medical Research Foundation of Oregon and an institutional grant from the School of Medicine, University of Oregon Health Sciences Center.

17. Received for publication July 26, 1979

18. Accepted for publication March 24, 1980 